\title{
Pengaruh Jenis Tulangan Terhadap Efektifitas Kinerja Balok Beton Bertulang
}

\author{
Elfania Bastian \\ Fakultas Teknik, Univeristas Muhammadiyah Sumatera Barat \\ email: elfania_bastian@ymail.com
}

\begin{abstract}
Balok merupakan bagian penting dari sebuah konstruksi bangunan. Inovasi-inovasi untuk meningkatka kualitas dan kemapuan balok dalam menahan beban terus dilakukan. Salah satu bentuk inovasi pada konstruksi balok beton bertulang adalah variasi jenis tulangan. Pada penelitian ini dilakukan analisis pada balok dengan jenis tulangan Baja dan GFRP (Glass Fibre Reinforced Polymer. GFRP dipilih karena material ini memiliki kapasitas leleh (fy) yang lebih tinggi dibandingkan baja, namun memiliki nilai elastisitas yang lebih rendah. Pengaruh fy dan elastisitas ini di analisis pada balok dengan variasi rasio tinggi efektif dan bentang geser (a/d). Dari hasil pengujian menggunakan program berbasis bahasa Fortran, diperoleh hasil berupa grafik load dan deflection. Hasil pengujian menunjukkan bahwa balok dengan tulangan GFRP mampu meningkatkan kemampuan balok menahan beban sebesar a) 24,27\%, (b) 24,26\%, (c) 24,26\%, dan (d) 24,28\%. Dan pada grafik juga terlihat bahwa balok dengan tulangan GFRP memiliki deformasi yang lebih besar.
\end{abstract}

Keywords: GFRP, Beton Bertulang, Kapasitas Balok

\section{PENDAHULUAN}

Sebuah konstruksi diharapkan mampu untuk menahan beban tertentu sesuai dengan umur rencana. Salah satu konstruksi yang paling sering digunakan adalah konstruksi menggunakan beton bertulang. Material konstruksi beton bertulang mempunyai sifat yang unik dibandingkan dengan material lain, hal ini disebabkan oleh beton bertulang adalah material konstruksi yang menggunakan dua jenis bahan yang berbeda secara bersamaan yaitu beton polos, yang memiliki kekuatan tekan yang tinggi akan tetapi mempunyai kekuatan tarik yang rendah, dan batanganbatangan baja yang ditanamkan di dalam beton yang dapat memberikan kekuatan tarik yang diperlukan.

Kuat tekan beton jauh lebih besar dari kuat tariknya sehingga dalam penggunaannya sebagai komponen struktural dalam bangunan sering dikombinasikan dengan batang tulangan baja yang berfungsi sebagai pemikul tegangan tarik. Sehingga dengan kombinasi tersebut dapat menutupi kelemahan dari beton tersebut. Kemampuan beton dalam memikul tegangan tekan ini yang selalu dikaitkan dengan peranan utama dari beton tersebut.

\section{Baja Tulangan}

Baja adalah logam campuran yang tediri dari besi $(\mathrm{Fe})$ dan karbon (C). Jadi baja berbeda dengan besi $(\mathrm{Fe})$, alumunium $(\mathrm{Al})$, seng $(\mathrm{Zn})$, tembagga $(\mathrm{Cu})$, dan titanium $(\mathrm{Ti})$ yang merupakan logam murni. Baja ditemukan ketika dilakukan penempaan terjadi pencampuran besi dengan bahan karbon pada proses pembakaran, sehingga membentuk baja yang mempunyai kekuatan yang lebih besar dari pada besi.

Disamping kekuatannya yang besar untuk menahan kekuatan tarik dan kekuatan tekan tanpa membutuhkan banyak volume, baja juga mempunyai sifat-sifat lain yang menguntungkan sehingga menjadikannya sebagai salah satu material yang umum dipakai, diantaranya;

a. Kekuatan tinggi

b. Kemudahan pemasangan

c. Keseragaman

d. Daktilitas ( keliatan )

e. Modulud Elastisitas Besar

Salah satu dari sifat baja yang paling menguntungkan dalam konstruksi adalah elastisitasnya. Dengan modulus yang besar, struktur akan cukup kaku sehingga dapat memberikan kenyamanan bagi pemakai. Jika dibandingkan dengan bahan yang lain, untuk regangan yang sama baja akan mengalami tegangan yang lebih besar sehingga kekuatannya lebih optimal. 


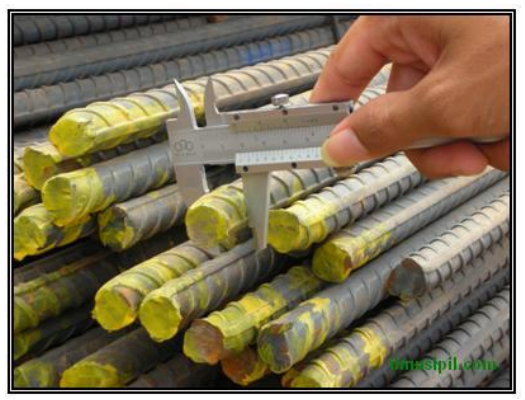

Gambar 1. Tulangan Baja Sumber:

http://tazziemania.wordpress.com/link-tazzie/

\section{Tulangan GFRP}

Glass Fiber Reinforced Polymer (GFRP) adalah material komposit yang terdiri dari fibre (serat) glass yang disatukan zat matrik, seperti epoxy atau polyester. Matrik itu sendiri berfungsi sebagai media penyalur tegangan ke serat dan melindungi serat dari pengaruh lingkungan yang agresif (Feldman dan Hartono, 1995).

Bahan GFRP sebagai pengganti tulangan baja memiliki keunggulan yakni; secara alamiah lebih tahan karat, berkekuatan tinggi untuk menahan gaya tarik, berbobot ringan, bersifat transparansi terhadap medan magnet listrik, dan dan kemudahan dalam fabrikasi serta penyetelan kontruksi pembangunan.

Material GFRP memiliki kapasitas tarik yang lebih tinggi dibandingkan material baja. Sehingga memungkin jika digunakan pada konstruksi beton bertulang untuk meningkatkan kapasitas beton bertulang dalam menahan beban. Namun, material ini memiliki nilai elastisitas yang lebih rendah.

\section{METODE PENELITIAN}

Prosedur kerja yang penulis lakukan adalah sebagai berikut:

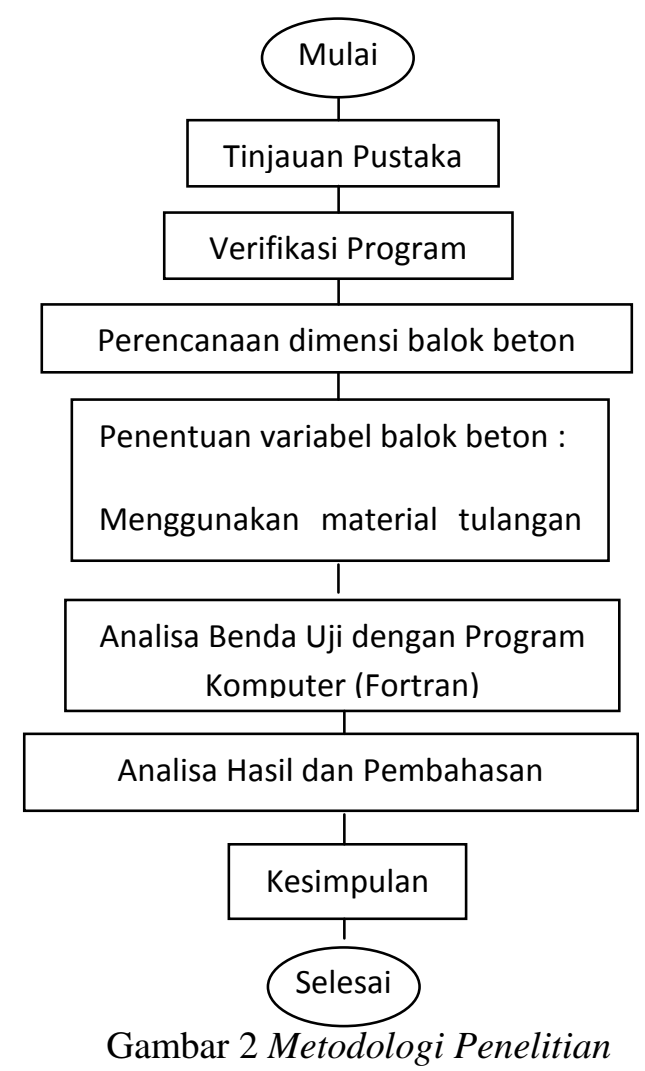

Material

Tabel 1. Propertis material beton

\begin{tabular}{|c|c|c|c|}
\hline Propertis & Notasi & Satuan & Besar \\
\hline $\begin{array}{c}\text { Elastic } \\
\text { Modulus }\end{array}$ & $\mathrm{Ec}$ & $\mathrm{MPa}$ & $3.03 \mathrm{E}+04$ \\
\hline $\begin{array}{c}\text { Poisson'is } \\
\text { Ratio }\end{array}$ & $\square$ & - & 0.02 \\
\hline $\begin{array}{c}\text { Tensile } \\
\text { Strength }\end{array}$ & $\mathrm{Ft}$ & $\mathrm{MPa}$ & 2.582 \\
\hline $\begin{array}{c}\text { Compressive } \\
\text { Strength }\end{array}$ & $\mathrm{Fc}$ & $\mathrm{MPa}$ & 30 \\
\hline
\end{tabular}

Tabel 2. Propertis material reinforced baja

\begin{tabular}{|c|c|c|c|}
\hline Propertis & Notasi & Satuan & Besar \\
\hline $\begin{array}{c}\text { Elastic } \\
\text { Modulus }\end{array}$ & $\mathrm{E}$ & $\mathrm{MPa}$ & $2.00 \mathrm{E}+05$ \\
\hline Regangan & $\square \lim$ & - & 0.05 \\
\hline $\begin{array}{c}\text { Tegangan } \\
\text { Yield }\end{array}$ & $\square \mathrm{y}$ & $\mathrm{MPa}$ & 500 \\
\hline $\begin{array}{c}\text { Tegangan } \\
\text { Ultimate }\end{array}$ & $\square \mathrm{t}$ & $\mathrm{MPa}$ & 630 \\
\hline
\end{tabular}

Tabel 3. Propertis material reinforced GFRP 
Vol. I No.2 Juni 2018

http://joernal.umsb.ac.id/index.php/RANGTEKNIKJOURNAL

\begin{tabular}{|c|c|c|c|}
\hline Propertis & Notasi & Satuan & Besar \\
\hline $\begin{array}{c}\text { Elastic } \\
\text { Modulus }\end{array}$ & $\mathrm{E}$ & $\mathrm{MPa}$ & $5.15 \mathrm{E}+04$ \\
\hline Regangan & $\square \mathrm{lim}$ & - & 0.02 \\
\hline $\begin{array}{c}\text { Tegangan } \\
\text { Yield }\end{array}$ & $\square \mathrm{y}$ & $\mathrm{MPa}$ & 769.4 \\
\hline $\begin{array}{c}\text { Tegangan } \\
\text { Ultimate }\end{array}$ & $\square \mathrm{t}$ & $\mathrm{MPa}$ & 769.4 \\
\hline
\end{tabular}

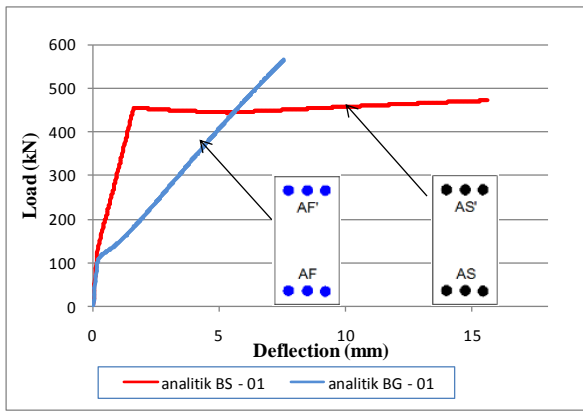

a. $\mathbf{a} / \mathbf{d}=\mathbf{1}$

\section{Variasi Model Numerik}

Balok beton bertulang di modelkan dengan variasi rasio bentang geser $(\mathrm{a} / \mathrm{d})$ yaitu $\mathrm{a} / \mathrm{d}=1$, $\mathrm{a} / \mathrm{d}=2$, $\mathrm{a} / \mathrm{d}=3$ dan $\mathrm{a} / \mathrm{d}=4$. Analisis dilakukan pada balok beton bertulang dengan penampang dan ukuran seperti yang terlihat pada gambar 3

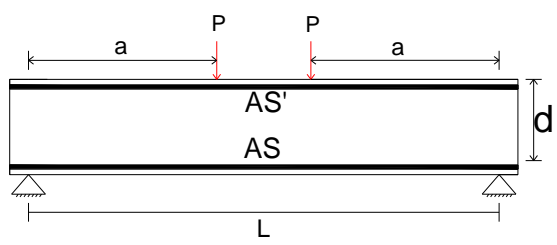

Gambar 3 Penampang balok beton bertulang untuk pengujian

Tabel 4. Propertis Balok Beton Bertulang

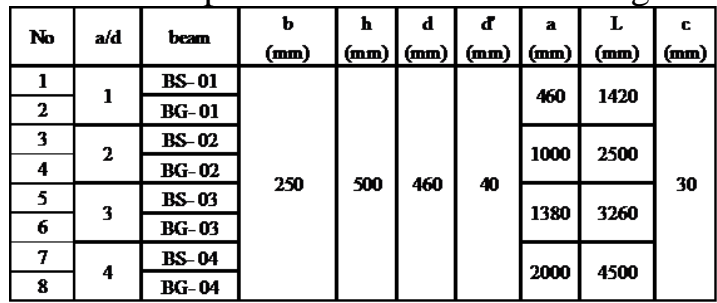

\section{HASIL DAN PEMBAHASAN}

Setelah dilakukan analisa secara numeric pada balok beton bertulang diperoleh hasil berupa grafik load dan deflection. Analisa dilakukan pada balok dengan a/d berbeda hal ini bertujuan untuk melihat perilaku balok baik pada balok lentur $(\mathrm{a} / \mathrm{d}>2,5)$ dan balok geser $(\mathrm{a} / \mathrm{d}<2,5)$ yang diberi tulangan Baja dan GFRP. Hasil analisa terlihat pada gambar 4 .

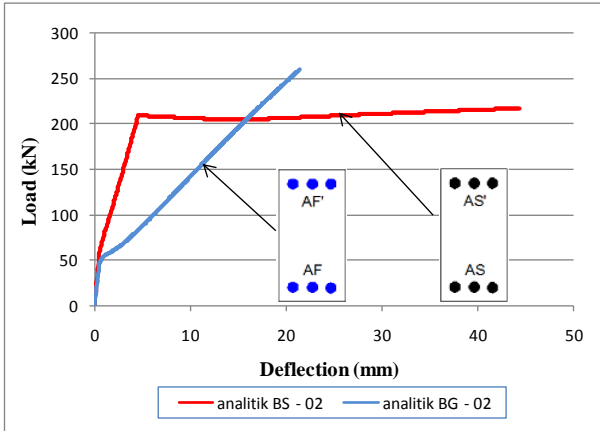

b. $\mathbf{a} / \mathbf{d}=\mathbf{2}$

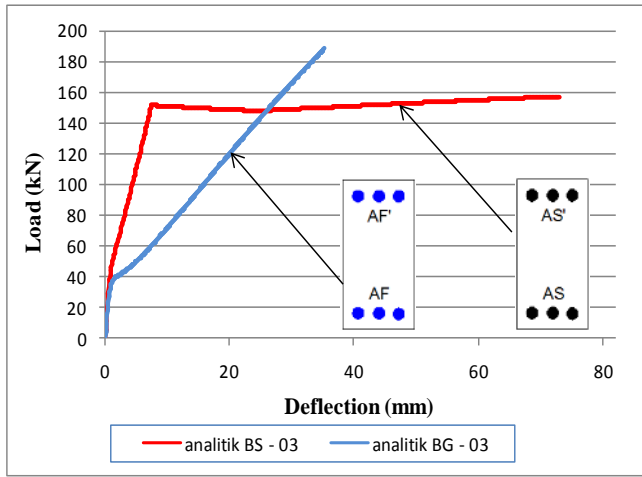

d. $\mathbf{a} / \mathbf{d}=\mathbf{3}$

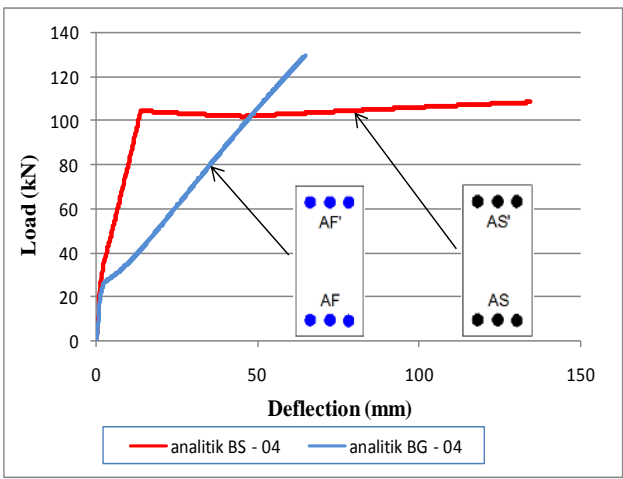

e. $a / d=4$

Gambar 4. Load - Deflection balok dengan tulangan baja dan tulangan GFRP tanpa CFRP plate 
Pada penulisan ini dilakukan analisis pada dua jenis material yang berbeda yaitu baja dan GFRP. Hal yang paling mendasar dari perbedaan baja dan GFRP adalah Elastisitasnya, GFRP memiliki elastistas jauh lebih rendah dibandingkan baja yaitu Es = $200000 \mathrm{MPa}$ sedangkan GFRP Ef= $51477 \mathrm{MPa}$. Dan pada gambar 4 tergambar GFRP bersifat getas. Pada gambar diatas dapat dilihat bahwa deformasi balok dengan tulangan GFRP memiliki nilai lebih besar jika dibandingkan deformasi balok dengan tulangan baja, hal ini dipengaruhi oleh modulus elastisitas baja lebih besar jika dibandingkan dengan GFRP.

Namun, Balok dengan tulangan GFRP memiliki kemampuan menahan beban lebih besar dibandingkan balok dengan tulangan baja. Pada gambar terlihat bahwa kempuan balok meningkat sebesar (a) $24,27 \%$, (b) $24,26 \%$, (c) $24,26 \%$, dan (d) $24,28 \%$. Hal ini dipengaruhi oleh fy GFRP lebih tinggi dibandingkan tulangan baja.

\section{SIMPULAN}

Berdasarkan hasil dari analisa numerik diketahui bahwa :

1. Elastisitas tulangan yang digunakan pada balok beton betulang memiliki pengaruh yang besar terhadap deformasi.

2. Analisis diperoleh hasil tulangan GFRP mampu meningkatkan kemampuan menahan beban sebesar (a) $24,27 \%$, (b) $24,26 \%$, (c) $24,26 \%$, dan (d) $24,28 \%$.

\section{UCAPAN TERIMAKASIH}

Alhamdulillah dengan rahmat Allah penulis dapat menyelesaikan penelitian ini. Terimakasih untuk keluarga, dan FT.UMSB atas dukungan dan doa.

\section{DAFTAR PUSTAKA}

Baja Tulangan Beton (SII 0136-84)

Cervenka, V. Jendele, L. and Cervenka, J. "ATENA Program Documentation Part 1, Theory" Prague, February 23. 2011.

Jack,C .Cormac, MC. "Desain Beton Bertulang”. Erlangga, Jakarta. 2004.

Jensen, A, Chenoweth,H. "Kekuatan Bahan Terapan”. Erlangga, Jakarta. 1991

Larralde,J.and Rodriguez. Silva. "Bond and Slip of FRP Rebars in Concrete". Journal of Materials in Civil
Engineering, Vol. 5, No.1. February, 1993

Morita, S. and Fujii, S. (1982), "Bond Capacity of Deformed Bars Due to Splitting of Surrounding Concrete", Bond in Concrete, edited by Bartos. P., Applied Science Publisher, pp. 331-341.

Paulay, T and R.Park. "Reinforced Concrete Structure". John Wiley \&Sons. Inc. United States of America. 1975

$\begin{array}{lr}\text { Fakultas Teknik UMSB } & \text { ISSN 2599-2081 } \\ \text { EISSN 2599-2090 }\end{array}$

